\title{
Correlation Between Anti-TNF Serum Levels and Endoscopic Inflammation in Inflammatory Bowel Disease Patients
}

\author{
María Chaparro ${ }^{1,18} \cdot$ Manuel Barreiro-de Acosta $^{2} \cdot$ Ana Echarri $^{3} \cdot$ Rosendo Almendros $^{4} \cdot$ Jesús Barrio $^{5} \cdot$ Jordina Llao $^{6}$. \\ Fernando Gomollón ${ }^{7,18}$. Maribel Vera ${ }^{8}$. José Luis Cabriada ${ }^{9} \cdot J_{0}$ Jordi Guardiola ${ }^{10} \cdot$ Iván Guerra $^{11} \cdot$ Belén Beltrán $^{12,18}$. \\ Oscar Roncero ${ }^{13}$. David Busquets ${ }^{14}$. Carlos Taxonera ${ }^{15} \cdot$ Xavier Calvet $^{16,18} \cdot$ Rocío Ferreiro-Iglesias $^{2}$. \\ Virginia Ollero Pena ${ }^{3} \cdot$ David Bernardo $^{1,18} \cdot$ María G. Donday ${ }^{1,18} \cdot$ Ana Garre $^{1,18} \cdot$ Ana Godino $^{17} \cdot$ Ana Díaz $^{17}$. \\ Javier P. Gisbert ${ }^{1,18}$
}

Received: 10 August 2018 / Accepted: 29 October 2018

(c) Springer Science+Business Media, LLC, part of Springer Nature 2018

\begin{abstract}
Objectives (a) To evaluate the diagnostic accuracy of anti-TNF trough levels to predict mucosal healing in inflammatory bowel disease (IBD); (b) to determine the best cut-off point to predict mucosal healing in IBD patients treated with anti-TNF. Methods This is a multicenter, prospective study. IBD patients under anti-TNF treatment for at least 6 months that had to undergo an endoscopy were included. Mucosal healing was defined as: Simple endoscopic score for Crohn's Disease $<3$ for Crohn's disease (CD), Rutgeerts score $<\mathrm{i} 2$ for CD in postoperative setting, or Mayo endoscopic score $\leq 1$ for ulcerative colitis (UC). Anti-TNF concentrations were measured using SMART ELISAs at trough.

Results A total of 182 patients were included. Anti-TNF trough levels were significantly higher among patients that had mucosal healing than among those who did not. The area under the curve of infliximab for mucosal healing was 0.63 (best cutoff value $3.4 \mu \mathrm{g} / \mathrm{mL}$ ), and for adalimumab 0.60 (best cutoff value $7.2 \mu \mathrm{g} / \mathrm{mL}$ ). In the multivariate analysis, having antiTNF drug levels above the cutoff values [odds ratio (OR) 3.1]) and having UC instead of CD (OR 4) were associated with a higher probability of having mucosal healing. Additionally, the need for an escalated dosage (OR 0.2) and current smoking habit (OR 0.2) were also associated with a lower probability of mucosal healing.

Conclusions There was an association between anti-TNF trough levels and mucosal healing in IBD patients; however, the accuracy of the determination of infliximab and adalimumab concentrations able to predict mucosal healing was suboptimal.
\end{abstract}

Keywords Anti-TNF · Tumor necrosis factor alpha · Trough levels · Mucosal healing · Infliximab · Adalimumab · Inflammatory bowel disease $\cdot$ Crohn's disease $\cdot$ Ulcerative colitis

$\begin{array}{ll}\text { Abbreviations } \\ \text { IBD } & \text { Inflammatory bowel disease } \\ \text { CD } & \text { Crohn's disease } \\ \text { UC } & \text { Ulcerative colitis } \\ \text { OR } & \text { Odds ratio } \\ \text { anti-TNF } & \text { Anti-tumor necrosis factor } \\ \text { SD } & \text { Standard deviation } \\ \text { 95\% CI } & 95 \% \text { confidence interval } \\ \text { ROC } & \text { Receiver operating characteristic curve }\end{array}$

María Chaparro and Javier P. Gisbert are both the guarantors of the article.

María Chaparro

mariachs2005@gmail.com $\begin{array}{ll}\text { AUC } & \text { Area under the curve } \\ \text { PPV } & \text { Positive predictive value } \\ \text { NPV } & \text { Negative predictive value }\end{array}$

\section{Introduction}

Approximately two-thirds of patients with inflammatory bowel disease (IBD) initially respond to treatment with anti-tumor necrosis factor (anti-TNF) drugs. However, efficacy is not sustained over time, since a relevant proportion of patients lose the response. It has been estimated in several studies that $25-40 \%$ of the patients who present initial response to infliximab subsequently lose it, requiring a change in therapy or a dose adjustment [1-3].

Extended author information available on the last page of the article 
Serum concentration of the anti-TNF drug is one of the factors that could be more relevant in loss of response phenomena [4]. Given that its true clinical utility has not been established yet, measurement of anti-TNF drug levels is not routinely performed in clinical practice. Two clinical scenarios have been proposed in which this measurement might be relevant. First, treatment with anti-TNF drugs adjusted for drug levels could improve both the duration of response and the safety and cost-effectiveness of the treatment. However, results from both TAXIT and TAILORIX trials failed to show a consistent clinical benefit from the adjustment of treatment based on drug levels, although this strategy led to a more efficient use of the drug [5, 6]. Nevertheless, cutoff values for therapeutic or subtherapeutic levels of anti-TNF drugs were established based only on clinical — but not endoscopic - activity evaluation. Second, therapeutic drug monitoring of anti-TNF drugs is useful in the case of loss of response to treatment [7,8].

Although the strategy to optimize treatment with anti-TNF drugs seems a promising tool to improve the effectiveness and efficiency of these drugs, its use in IBD is limited. This is due to several causes: a) heterogeneity of measurement methods; b) difficulty in interpreting test results because therapeutic cutoff points are not defined; and c) controversial evidence about its efficacy and efficiency in clinical practice $[9,10]$.

As mentioned above, identification of anti-TNF cutoff values is crucial. Initially, trials applied the limit of detection of the assay as a pragmatic cutoff value. Further investigations proposed new cutoff values considering clinical activity. Although clinical remission has been considered as a major goal of therapy in the treatment of IBD, in recent years endoscopic remission - mucosal healing — has been proposed as a measure of treatment success [11]. In fact, the incongruence between primarily symptom-based disease activity indexes and objective measures of inflammation has recently led the regulatory agencies to request for documentation showing efficacy by objective measures to approve a new drug.

Thus, given the importance of mucosal healing and the demonstrated benefits of therapeutic drug monitoring in the use of anti-TNF therapy, together with the paucity of information about the correlation between anti-TNF drug levels and mucosal healing, we performed the present study aiming to know the correlation between anti-TNF drug levels and mucosal healing. In addition, we aimed to define the optimal drug level required to have the highest probability of achieving mucosal healing.

\section{Methods}

\section{Patients}

One hundred eighty-two consecutive patients diagnosed with Crohn's disease (CD) or ulcerative colitis (UC) based on clinical, radiological, endoscopic, and histological evaluations were included. Patients were under anti-TNF treatment in stable doses for at least 6 months and underwent a colonoscopy due to clinical practice. Exclusion criteria were as follows: to have CD affecting intestinal segments not accessible to endoscopy; to have an incomplete endoscopic examination (an incomplete ileocolonoscopy in $\mathrm{CD}$ or incomplete colonoscopy in $\mathrm{UC}$ ); to have received anti-TNF only for perianal disease; or to be treated with anti-TNF for prophylaxis of postoperative CD recurrence or pouchitis. However, CD patients treated with anti-TNF drugs for active postoperative recurrence were allowed for inclusion. The study was approved by the Research Ethics Committee of the Hospital Universitario de La Princesa (Madrid, Spain).

\section{Study Design}

We conducted a prospective, multicenter cohort study; sixteen IBD units across Spain participated in this project. Clinical and endoscopic evaluation was assessed, and blood samples were obtained just before the administration of the drug (trough levels) within a month after the endoscopic evaluation. The principal variable was mucosal healing (see Endoscopic activity assessment section for definition).

\section{Data Collection}

Data were prospectively obtained from medical records. Variables included in the database were as follows: IBD type (location and behavior), age at diagnosis of IBD, time of evolution of the disease, smoking habit, surgical interventions due to IBD, concomitant treatment with immunosuppressants, previous treatment with anti-TNF drugs, type of anti-TNF drug, anti-TNF dosage (standard or optimized), and clinical and endoscopic activity.

Study data were collected and managed using the REDCap electronic data capture tool hosted at Asociación Española de Gastroenterología (AEG; http://www.aegastro. es) [12]. AEG is a nonprofit scientific and medical society focused on gastroenterology, and it provides this service free of charge, with the sole aim of promoting independent investigator-driven research. REDCap (Research Electronic Data Capture) is a secure, Web-based application designed to support data capture for research studies, providing: (1) an intuitive interface for validated data entry; (2) audit trails for tracking data manipulation and export procedures; (3) automated export procedures for seamless data downloads to common statistical packages; and (4) procedures for importing data from external sources. 


\section{Endoscopic Activity Assessment}

The calculation of endoscopic activity was based on the Mayo index for UC, Simple endoscopic score for CD (SESCD) for CD [13] in patients without intestinal resection, and Rutgeerts score in $\mathrm{CD}$ patients with ileocolic resection [14]. Mucosal healing was defined as a SES-CD $<3$ for CD patients, Rutgeerts score $<\mathrm{i} 2$ for $\mathrm{CD}$ patients in the postoperative setting, or Mayo endoscopic score $<2$ for UC patients [15].

All endoscopists were blinded to clinical assessment, biological data, and the anti-TNF trough level measurement.

\section{Samples}

Blood samples were obtained in $10-\mathrm{mL}$ biochemical tubes. The time elapsed between the analytical determination and the completion of the endoscopy did not exceed 30 days. Each 10-mL tube was centrifuged for $10 \mathrm{~min}$ (3000 rpm at $25^{\circ} \mathrm{C}$ ), and the supernatant cryopreserved following the kit manufacturer's instructions at a maximum temperature of $-20{ }^{\circ} \mathrm{C}$ until centrally analyzed by SMART ELISAs in Sanquin Laboratories (Amsterdam, The Netherlands).

\section{Statistical Analysis}

Quantitative variables were expressed as mean and standard deviation (SD) or median and interquartile range, depending on whether or not they followed a normal distribution. Qualitative variables were expressed as frequencies with their 95\% confidence intervals ( $95 \% \mathrm{CI})$.

In the univariate analysis, variables were compared considering the presence of mucosal healing as the dependent variable. Qualitative variables were compared using the Chi-square test. The quantitative variables were compared by the Student's $t$ test or a nonparametric test in the case of variables that did not follow a normal distribution.

In the main analysis, a receiver operating characteristic curve (ROC) analysis was performed using mucosal healing as classification variable, and area under the ROC (AUC) was determined for both adalimumab and infliximab. The optimal cutoff point ("therapeutic drug level"), for each anti-TNF drug (adalimumab and infliximab) was selected. Sensitivity, specificity, positive predictive value (PPV), and negative predictive value (NPV) were calculated for the selected cutoff point. In the next step, infliximab and adalimumab concentrations were recoded as a categorical variable named "Drug level" according to the cutoff concentration selected for each drug considering the ROC. Drug level was considered positive (equal to or above the cutoff) or negative (below the cutoff). Variables associated with mucosal healing in the univariate analysis were combined in a stepwise multivariate logistic regression model to identify variables independently associated with mucosal healing. For this analysis, the variable "Drug level" was considered, instead of the drug concentration, to evaluate the influence of anti-TNF levels (infliximab together with adalimumab) in mucosal healing. In addition, the same model was repeated including infliximab and adalimumab concentrations separately, to analyze the impact of changes in the anti-TNF concentration in the probability of having mucosal healing.

\section{Results}

A total of 182 patients were included in the study. Of them, $92(50.5 \%)$ were male, $94(51 \%)$ were under adalimumab treatment, and $88(48.4 \%)$ were under infliximab treatment. Among patients treated with infliximab, 37 (42\%) were under concomitant treatment with immunosuppressants. Median infliximab concentration was similar in patients with and without immunosuppressants (3.8 vs. 3.4, $p=0.8$ ). In addition, 18 patients $(20.5 \%)$ treated with infliximab received an escalated dosage; median infliximab trough level was significantly higher in these patients $(6.2 \mathrm{vs} .3 .4 \mu \mathrm{g} / \mathrm{mL}$, $p=0.03$ ).

Within adalimumab patients, 33 (35\%) were under escalated treatment. Median adalimumab concentration was slightly higher in patients under escalated dosage than in those without dose intensification $(9.9$ vs. $6.5 \mu \mathrm{g} / \mathrm{mL}$, $p=0.06)$. In addition, 26 patients treated with adalimumab were on concomitant immunosuppressants. Median adalimumab concentration was similar in patients with and without concomitant immunosuppressants (6.4 vs. $5.6 \mu \mathrm{g} / \mathrm{mL}$, $p=0.2$ ).

Among the 182 included patients, 93 (51.1\%) had mucosal healing. The main characteristics of the study population based on the presence of mucosal healing are summarized in Table 1. ROC analysis showing the optimal cutoff values of both infliximab and adalimumab trough levels to predict mucosal healing is included in Fig. 1. The AUC of infliximab to predict mucosal healing was 0.63 , and the best cutoff point was $3.4 \mu \mathrm{g} / \mathrm{mL}$. The sensitivity, specificity, PPV, and NPV are summarized in Table 2. On the other hand, the AUC of adalimumab to predict mucosal healing was 0.60 and the best cutoff point was $7.2 \mu \mathrm{g} / \mathrm{mL}$. The sensitivity, specificity, PPV, and NPV are summarized in Table 2.

In the univariate analysis, several variables, such as tobacco consumption, having CD instead of UC, or previous infliximab therapy, were significantly associated with mucosal healing (Table 3). Of note, median infliximab trough levels were significantly higher in patients with mucosal healing than in those without mucosal healing $(4.8$ 
Table 1 Association of baseline characteristics of the study population with the presence of mucosal healing (univariate analysis)

\begin{tabular}{|c|c|c|c|}
\hline & Mucosal healing & No mucosal healing & $p$ \\
\hline Female gender, $n(\%)$ & $51(54.8)$ & $39(43.8)$ & N.S. \\
\hline Active smoking, $n(\%)$ & $11(11.8)$ & $39(43.8)$ & $<0.001$ \\
\hline Crohn's disease, $n(\%)$ & $51(54.8)$ & $76(85.4)$ & $<0.001$ \\
\hline \multicolumn{4}{|l|}{ Location } \\
\hline Ileal & $21(22.6)$ & $28(31.5)$ & \multirow[t]{4}{*}{ N.S. } \\
\hline Colonic & $11(11.8)$ & $14(15.7)$ & \\
\hline Ileocolonic & $18(19.4)$ & $34(38.2)$ & \\
\hline Upper gastrointestinal tract & $2(2.2)$ & $2(2.2)$ & \\
\hline \multicolumn{4}{|l|}{ Behavior } \\
\hline Inflammatory & $30(58.8)$ & 37 (48.7) & \multirow[t]{3}{*}{ N.S. } \\
\hline Stricturing & $10(19.6)$ & $24(31.6)$ & \\
\hline Fistulizing & $11(21.6)$ & $15(19.7)$ & \\
\hline Perianal & $36(70.6)$ & $49(64.5)$ & N.S. \\
\hline \multicolumn{4}{|l|}{ Ulcerative colitis } \\
\hline Extensive & $29(69)$ & $10(76.9)$ & \multirow[t]{2}{*}{ N.S. } \\
\hline Left-sided & $13(31)$ & $3(23.1)$ & \\
\hline Previous surgery, $n(\%)$ & $17(18.3)$ & $32(36)$ & $<0.01$ \\
\hline Drug, infliximab, $n(\%)$ & $58(62.4)$ & $30(33.7)$ & $<0.001$ \\
\hline Escalated dosage, $n(\%)$ & $16(17.2)$ & $35(39.3)$ & $<0.01$ \\
\hline Previous anti-TNF exposure, $n(\%)$ & $15(16)$ & $33(37)$ & $<0.001$ \\
\hline Concomitant immunosuppressants, $n(\%)$ & $35(37.6)$ & $28(31.5)$ & N.S. \\
\hline Anti-TNF concentration over the threshold, $n(\%)$ & $58(62.4)$ & $40(44.9)$ & 0.01 \\
\hline Age (mean, SD), years & $45.3(14.2)$ & $40.3(11.4)$ & 0.01 \\
\hline Time of evolution of the disease (mean, SD), months & $140.4(96.3)$ & $143(94.6)$ & N.S. \\
\hline $\begin{array}{l}\text { Duration of treatment with current anti-TNF (median, } \\
\text { IQR), months }\end{array}$ & $39(6-123)$ & $26(6-110)$ & N.S. \\
\hline
\end{tabular}

$N . S$. non-statistically significant, $S D$ standard deviation, $I Q R$ interquartile range vs. $3 \mu \mathrm{g} / \mathrm{mL}, p=0.03$ ) (Fig. 2). Mean adalimumab trough levels were also significantly higher in patients with mucosal healing (9.6 vs. $7.1 \mu \mathrm{g} / \mathrm{mL}, p=0.04$ ) (Fig. 2).

In the multivariate analysis, anti-TNF trough levels were classified as positive or negative based on the optimal cutoff value chosen from the ROCs. In this regard, having antiTNF trough levels above the cutoff concentration (OR 3.1, 95\% CI 1.5-6.5) and having UC instead of CD (OR 4.1, 95\% CI 1.7-9.5) were significantly associated with a higher probability of mucosal healing. Additionally, smokers and patients that needed escalated dosage had lower probability of mucosal healing (Table 3).

The model was repeated considering infliximab and adalimumab concentration as continuous variables to analyze the impact that the change in anti-TNF concentration exerted on the probability of having mucosal healing. With respect to adalimumab, trough concentration was significantly associated with higher probability of mucosal healing (OR 1.09, 95\% CI 1.008-1.1). The model confirmed that receiving escalated dosage and smoking habit were significantly associated with a lower probability of mucosal healing (Table 3).
Infliximab trough levels were also associated with higher probability of mucosal healing (OR 1.2, 95\% CI 1.01-1.4), as well as having UC instead of CD. Conversely, to be treated with an escalated dosage and smoking habit were significantly associated with lower probability of mucosal healing (Table 3).

Anti-drug antibodies were measured only in patients with undetectable anti-TNF serum levels. Therefore, it was not possible to analyze the effect of anti-drug antibodies on anti-TNF serum concentration. A total of 28 patients had anti-drug levels below the limit of detection: Of them, 16 $(57 \%)$ were also negative for anti-drug antibodies, whereas $12(43 \%)$ were positive for anti-drug antibodies.

\section{Discussion}

To our knowledge, this is the largest prospective study designed to assess the correlation between anti-TNF trough levels and mucosal healing in IBD patients. We found that there is an association between anti-TNF serum levels (infliximab and adalimumab) and the presence of 

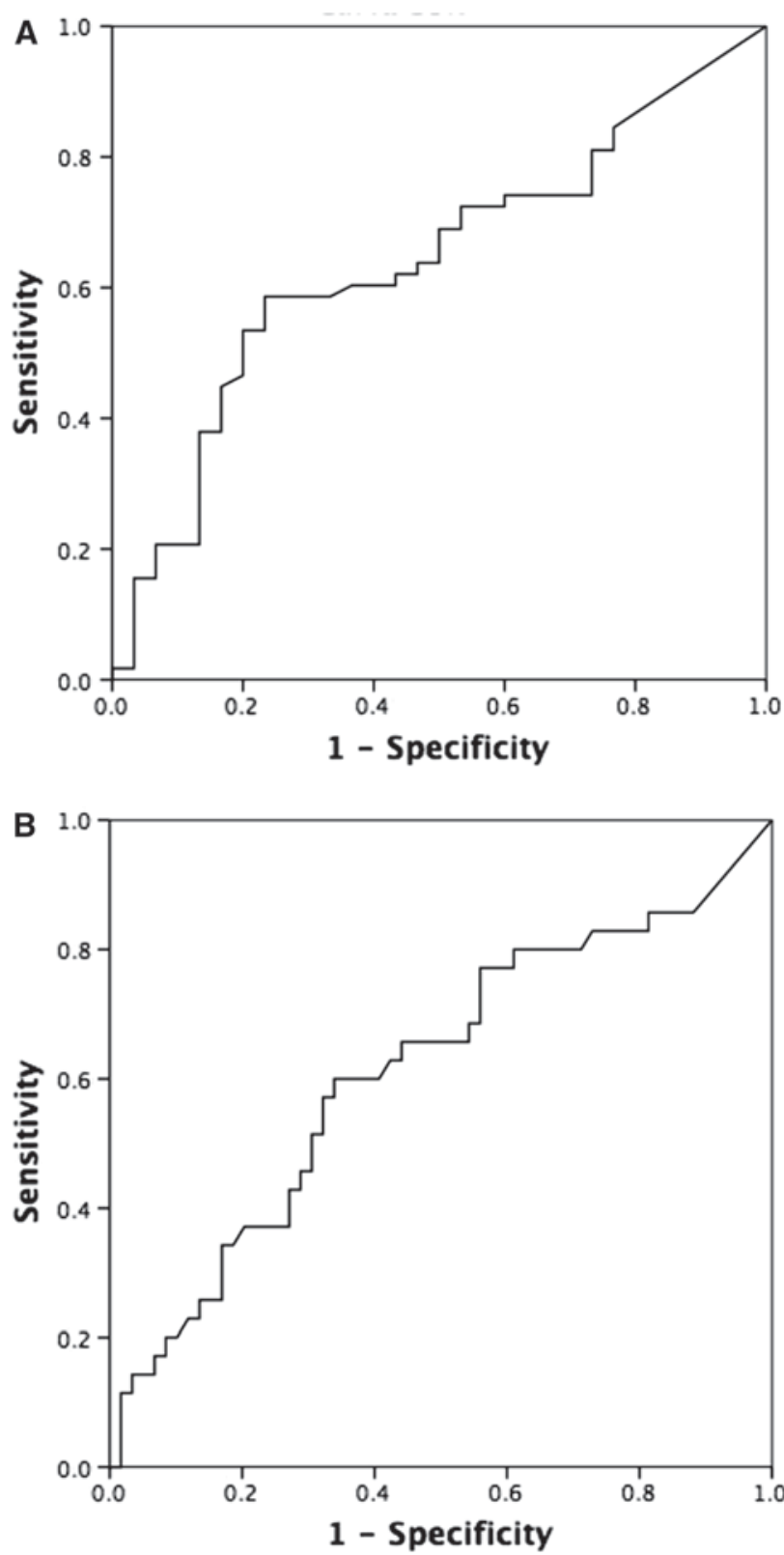

Fig. 1 Receiver operating characteristic curves (ROCs) showing the correlation between infliximab levels (a) or adalimumab levels (b) and the presence of mucosal healing

mucosal healing. We also determined infliximab and adalimumab cutoff points to predict mucosal healing. Nevertheless, the accuracy of this determination was poor (as the areas under the ROCs were below 0.7). This means that a relevant proportion of patients would be misclassified based on the determination of anti-TNF serum levels.

Based on our results, we proposed a concentration of $3.4 \mu \mathrm{g} / \mathrm{mL}$ as the best cutoff point for infliximab, and $7.2 \mu \mathrm{g} / \mathrm{mL}$ for adalimumab. The probability of having mucosal healing was threefold higher among patients with anti-TNF serum levels over these cutoff values.

Currently, information on the correlation between antiTNF levels and the presence of endoscopic lesions is very scarce. Up to now, few studies have been published on this subject and most of them included a limited number of patients. Besides, several of those studies performed random measures (instead of trough levels), while many of them also used non-validated indexes for the classification of endoscopic activity [16-22] (Table 4). Furthermore, the concordance between the different assays is low [9, 10]. The diagnostic accuracy of anti-TNF levels for mucosal healing reported in those studies has been generally poor, with AUCs between 0.6 and 0.7 in most cases.

The highest accuracy of anti-TNF levels able to predict mucosal healing was reported by Morita et al. [22]. Authors included 42 patients that underwent a transanal enteroscopy with a mean intubation depth from the ileocecal valve of $51 \mathrm{~cm}$ (range $15-200 \mathrm{~cm}$ ). The AUC of adalimumab trough levels for mucosal healing was 0.79 (i.e., fair), but the precision of this estimation was low, as the 95\% CI of the AUC ranged from 0.65 to 0.93 . The adalimumab trough level that was best associated with mucosal healing was $7.9 \mu \mathrm{g} / \mathrm{mL}$. However, authors acknowledged that the study had several shortcomings such as a limited sample size or the use of the modified Rutgeerts scoring system to categorize endoscopic activity. The reliability of this scoring system has not been confirmed, and its validation should be performed. Taking all these limitations into account, authors suggested that their results should be interpreted with caution.

In our study, the best cutoff value for infliximab was 3.4 $\mu \mathrm{g} / \mathrm{mL}$. This figure is similar to that reported by Reinisch et al. [18] and Imaeda et al. [16], which were 3 and $4 \mu \mathrm{g} / \mathrm{mL}$, respectively. On the other hand, Ungar et al. considered that therapeutic levels of infliximab were those set at 6-10 $\mu \mathrm{g} /$ $\mathrm{mL}$ [21]. However, blood samples in this retrospective study were not obtained at trough, which could explain the higher therapeutic range proposed for infliximab concentration.
Table 2 Accuracy of antiTNF trough serum levels to predict mucosal healing in inflammatory bowel disease patients

\begin{tabular}{llllllc}
\hline Anti-TNF & AUC & $\begin{array}{l}\text { Best cutoff point } \\
(\mu \mathrm{g} / \mathrm{mL})\end{array}$ & $\begin{array}{l}\text { Sensitivity } \\
(\%)\end{array}$ & $\begin{array}{l}\text { Specificity } \\
(\%)\end{array}$ & PPV (\%) & NPV (\%) \\
\hline Infliximab & 0.63 & 3.4 & 60 & 60 & 73 & 42 \\
Adalimumab & 0.60 & 7.2 & 65 & 56 & 46 & 72 \\
\hline
\end{tabular}

$A U C$ area under the ROC, $P P V$ positive predictive value, $N P V$ negative predictive value 
Table 3 Factors associated with mucosal healing (a) in patients under infliximab (b) and adalimumab (c) treatment

\begin{tabular}{lllc}
\hline & Odds ratio & $\begin{array}{l}\text { 95\% Confidence } \\
\text { interval }\end{array}$ & $p$ \\
\hline (a) Overall group & & & \\
$\quad$ Anti-TNF concentration over the cutoff & 3.1 & $1.5-6.5$ & 0.002 \\
Optimized anti-TNF dosage & 0.2 & $0.08-0.4$ & $<0.001$ \\
Ulcerative colitis (vs. Crohn's disease) & 4.1 & $1.7-9.5$ & 0.001 \\
Smoking habit & 0.2 & $0.09-0.5$ & 0.001 \\
(b) Infliximab & & & 0.03 \\
Infliximab trough levels ( $\mu$ g/mL) & 1.2 & $1.01-1.4$ & 0.01 \\
Optimized dosage of infliximab & 0.1 & $0.04-0.6$ & 0.002 \\
Ulcerative colitis (vs. Crohn's disease) & 6.9 & $1.9-24.4$ & 0.09 \\
Smoking habit & 0.3 & $0.09-1.2$ & 0.03 \\
(c) Adalimumab & & & 0.01 \\
Adalimumab trough levels $(\mu \mathrm{g} / \mathrm{mL})$ & 1.09 & $1.008-1.1$ & 0.4 \\
Optimized dosage of infliximab & 0.2 & $0.07-0.6$ & 0.01 \\
Ulcerative colitis (vs. Crohn's disease) & 1.5 & $0.4-5.6$ & \\
Smoking habit & 0.2 & $0.07-0.7$ & \\
\hline
\end{tabular}

The cutoff value for adalimumab is higher than that proposed for infliximab, as reported by most studies. In the majority of these studies, including ours, adalimumab cutoff value was around $8 \mu \mathrm{g} / \mathrm{mL}$ [20-22]. However, the values proposed by Roblin and Zittan et al. were lower (around $4 \mu \mathrm{g} / \mathrm{mL}$ ). This is probably due to differences in the definition of mucosal healing since these authors defined mucosal healing just as the absence of ulcers, thereby allowing the presence of some inflammatory lesions such as edema, friability, or erosions.

In addition, in our study we identified several variables independently associated with mucosal healing. In this respect, having UC instead of CD was associated with a higher probability of mucosal healing. Some authors have also suggested that severe UC patients might need higher load of anti-TNF drugs during the induction [23]. However, our study included patients during the maintenance phase. $\mathrm{CD}$ is a transmural condition, and therefore, this could lead to the need of higher amount of drug to block inflammation. This observation needs to be confirmed in further studies.

In our study we also found that smoking habit was associated with a lower probability of mucosal healing. The relationship between smoking habit and poor outcomes in $\mathrm{CD}$ has been widely demonstrated, meaning higher need for surgery, medications, and postsurgical recurrence [24]. In our hands, around two-thirds of patients had CD and onethird had UC. Nevertheless, the variable remained significant after adjusting for IBD type in the multivariate analysis. Further studies are necessary to confirm whether smokers need higher anti-TNF levels to reach mucosal healing.

Finally, in the multivariate analysis, patients under escalated dosage had a lower probability of mucosal healing. Of note, dosage had been empirically escalated in our cohort
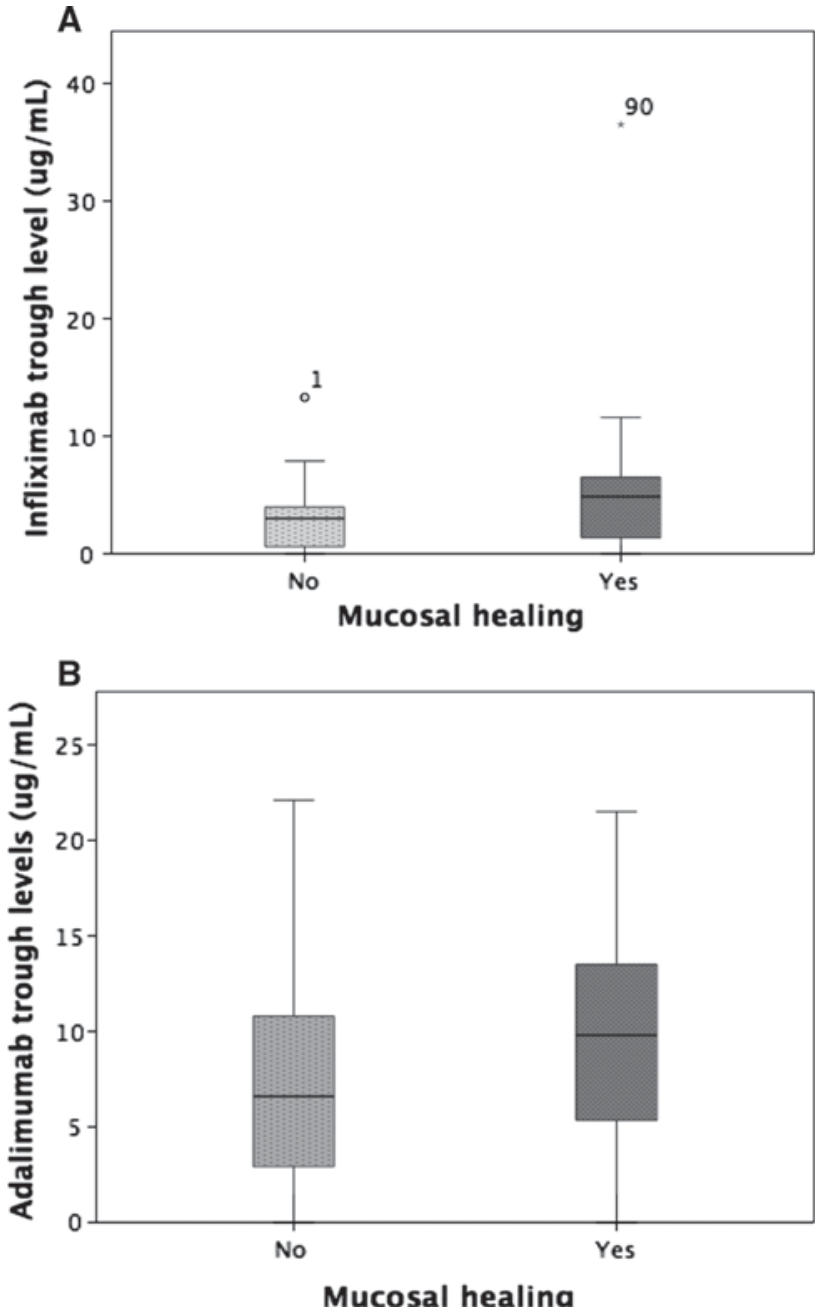

Fig. 2 Anti-TNF trough levels, infliximab (a) and adalimumab (b), in patients with mucosal healing versus those with endoscopically active disease 
Table 4 Published studies assessing the correlation between infliximab and adalimumab serum levels and mucosal healing in inflammatory bowel disease patients under maintenance treatment

\begin{tabular}{|c|c|c|c|c|c|c|c|c|}
\hline References & Design & $N$ & Anti-TNF & Assay & $\begin{array}{l}\text { Endoscopic } \\
\text { activity index }\end{array}$ & AUC & Cutoff & $\begin{array}{l}\text { Variables inde- } \\
\text { pendently associ- } \\
\text { ated with mucosal } \\
\text { healing }\end{array}$ \\
\hline $\begin{array}{l}\text { Imaeda et al. } \\
{[16]}\end{array}$ & $\mathrm{P}$ & $\begin{array}{l}45 \text { CD (78 } \\
\text { endosco- } \\
\text { pies) }\end{array}$ & IFX & ELISA & $\begin{array}{l}\text { Modified Rut- } \\
\text { geerts scoring } \\
\text { system }\end{array}$ & 0.63 & $4 \mu \mathrm{g} / \mathrm{mL}$ & - \\
\hline $\begin{array}{l}\text { Roblin et al. } \\
\text { [17] }\end{array}$ & $\mathrm{P}$ & $\begin{array}{l}22 \mathrm{CD} \\
18 \mathrm{UC}\end{array}$ & ADA & ELISA & $\begin{array}{l}\text { Absence of } \\
\text { ulcerations }\end{array}$ & 0.77 & $4.9 \mu \mathrm{g} / \mathrm{mL}$ & $\begin{array}{l}\text { ADA trough lev- } \\
\text { els and duration } \\
\text { of treatment }\end{array}$ \\
\hline $\begin{array}{l}\text { Reinisch et al. } \\
\text { [18] }\end{array}$ & $\mathrm{P}-\mathrm{H}$ & $123 \mathrm{CD}$ & IFX & $\begin{array}{l}\text { Sandwich } \\
\text { enzyme } \\
\text { immunoassay }\end{array}$ & $\begin{array}{l}\text { Absence of } \\
\text { ulcerations } \\
\text { and erosions }\end{array}$ & 0.63 & $3 \mu \mathrm{g} / \mathrm{mL}$ & $\begin{array}{l}\text { C-reactive protein } \\
\text { normalization } \\
\text { and IFX trough } \\
\text { levels }\end{array}$ \\
\hline Zittan et al. [19] & $\mathrm{P}$ & $60 \mathrm{CD}$ & $\begin{array}{l}\text { ADA (no trough } \\
\text { levels) }\end{array}$ & $\begin{array}{l}\text { Liquid phase } \\
\text { mobility shift } \\
\text { assay }\end{array}$ & $\begin{array}{l}\text { Absence of } \\
\text { ulcerations }\end{array}$ & - & $4 \mu \mathrm{g} / \mathrm{mL}$ & $\begin{array}{c}\text { Harvey-Bradshaw } \\
\text { index score and } \\
\text { ADA levels }\end{array}$ \\
\hline Yarur et al. [20] & $\mathrm{P}$ & $\begin{array}{l}59 \mathrm{CD} \\
7 \mathrm{UC}\end{array}$ & $\begin{array}{l}\text { ADA (no trough } \\
\text { levels) }\end{array}$ & $\begin{array}{l}\text { Homogeneous } \\
\text { mobility shift } \\
\text { assay }\end{array}$ & $\begin{array}{l}\text { Lack of inflam- } \\
\text { matory find- } \\
\text { ings }\end{array}$ & 0.76 & $7.8 \mu \mathrm{g} / \mathrm{mL}$ & - \\
\hline Ungar et al. [21] & $\mathrm{R}$ & $\begin{array}{l}111 \mathrm{CD} \\
34 \mathrm{UC}\end{array}$ & $\begin{array}{l}\text { ADA } \\
\text { IFX (no trough } \\
\quad \text { levels) }\end{array}$ & $\begin{array}{l}\text { Capture } \\
\text { enzyme-linked } \\
\text { immunoab- } \\
\text { sorbent assay }\end{array}$ & $\begin{array}{l}\text { SES-CD }<3 \\
\text { or endo- } \\
\text { scopic Mayo } \\
\text { score } \leq 1\end{array}$ & $\begin{array}{l}\text { ADA: } 0.7 \\
\text { IFX: } 0.75\end{array}$ & $\begin{array}{l}\text { ADA: } 8-12 \mu \mathrm{g} / \\
\text { mL } \\
\text { IFX: } 6-10 \mu \mathrm{g} / \\
\text { mL }\end{array}$ & $\begin{array}{l}\text { Serum IFX levels. } \\
\text { Serum ADA } \\
\text { levels and epi- } \\
\text { sodic treatment }\end{array}$ \\
\hline $\begin{array}{l}\text { Morita et al. } \\
{[22]}\end{array}$ & $\mathrm{P}$ & $42 \mathrm{CD}$ & ADA & ELISA & $\begin{array}{l}\text { Modified Rut- } \\
\text { geerts scoring } \\
\text { system }\end{array}$ & 0.79 & $7.9 \mu \mathrm{g} / \mathrm{mL}$ & - \\
\hline
\end{tabular}

$A D A$ adalimumab, $A U C$ area under the curve, $C D$ Crohn's disease, $I F X$ infliximab, $N$ number of patients, $P$ prospective, $P$ - $H$ post hoc, $R$ retrospective, $U C$ ulcerative colitis, $C D$ Crohn's disease

after losing response. Therefore, some of these patients could have lost response to the treatment either due to pharmacokinetic issues (where the escalation of the treatment would be the most beneficial choice) or due to pharmacodynamic problems. Thus, although patients under escalated dosage had higher anti-TNF levels than patients with standard dosage, the probability of having mucosal healing was lower.

Our study has some limitations. First of all, only patients with luminal CD were evaluated. Some authors suggested that patients with perianal CD need higher anti-TNF levels to reach remission. We could not provide data on this specific clinical scenario. However, the heterogeneity in the treatment of perianal disease (mainly due to the differences in the surgical approach to perianal fistula) would have created bias, making the interpretation of the results difficult. Moreover, there was a lack of centralized reading of endoscopic images in our study. However, all examinations were performed by endoscopists with wide experience in IBD, who were indeed responsible for those procedures in their centers.
Our study has several strengths. To the best of our knowledge, up to now, this is the largest prospective study evaluating the correlation between anti-TNF trough levels and mucosal healing (which should be the therapeutic goal) in the clinical practice setting. In fact, patients with incomplete ileocolonoscopies or those with affected intestinal segments non-accessible to endoscopy were excluded from the study. Furthermore, we have included a very homogeneous population of patients receiving anti-TNF drugs in the maintenance phase (not during the induction).

In conclusion, there is a relationship between infliximab and adalimumab trough levels, and mucosal healing in IBD patients. Nevertheless, the accuracy of the determination of anti-TNF serum concentrations able to predict mucosal healing is poor (AUC $<0.7$ ), meaning that a high proportion of patients would be misclassified based on anti-TNF serum levels. The best cutoff values for predicting mucosal healing are 3.4 and $7.2 \mu \mathrm{g} / \mathrm{mL}$ for infliximab and adalimumab, respectively. However, due to the low accuracy of the test, the results should be interpreted with caution in clinical practice. In addition, we have identified that smoking habit, having $\mathrm{CD}$ (vs. UC), and to be treated with escalated dosage 
of anti-TNF were independently associated with lower probability of mucosal healing. We believe that this large prospective study provides valuable information that can help with decision making in therapeutic drug monitoring setting.

Acknowledgments The authors wish to thank Sanquin for analyzing serum samples.

Author's contribution M. Chaparro and J.P. Gisbert conceived and designed this study. All the authors participated in the collection of data and samples of patients. M. Chaparro and J.P. Gisbert analyzed and interpreted the results and wrote the manuscript. All the authors critically reviewed the manuscript, and have read and approved the final version of the manuscript.

Funding This research was funded by grants from the Instituto de Salud Carlos III (FIS.12/02557 and PI13/00041) and the Ministerio de Economía (SAF2014-56642-JIN) from the Spanish Government.

\section{Compliance with ethical standards}

Conflict of interest María Chaparro has served as a speaker, or has received research or education funding from MSD, AbbVie, Hospira, Pfizer, Takeda, Janssen, Ferring, Shire Pharmaceuticals, Dr. Falk Pharma, and Tillotts Pharma. Manuel Barreiro-de Acosta has served as a speaker, has served as a consultant and advisory member for, or has received research funding from MSD, AbbVie, Hospira, Takeda, Janssen, Kern, Ferring, Faes Farma, Shire Pharmaceuticals, Dr. Falk Pharma, Chiesi, Gebro Pharma, Otsuka Pharmaceuticals, and Tillotts Pharma. Maribel Vera has served as speaker for Pfizer and a consultant and advisory member for Kern Pharma. Iván Guerra has served as speaker for Pfizer and a consultant and advisory member for Kern Pharma. Carlos Taxonera has served as a speaker, or a consultant and advisory member for MSD, AbbVie, Hospira, Pfizer, Takeda, Janssen, Ferring, Faes Farma, Shire Pharmaceuticals, Dr. Falk Pharma, and Gebro Pharma. Xavier Calvet has received grants for research from Abbott, MSD, Vifor fees for advisory boards form Abbott, MSD, Takeda and Vifor and has given lectures for Abbott, MSD, Takeda, Shire and Allergan. Rocío Ferreiro-Iglesias has served as a speaker for AbbVie, Shire y MSD. Javier P. Gisbert has served as a speaker, has served as a consultant and advisory member for, or has received research funding from MSD, AbbVie, Hospira, Pfizer, Kern Pharma, Biogen, Takeda, Janssen, Roche, Celgene, Ferring, Faes Farma, Shire Pharmaceuticals, Dr. Falk Pharma, Tillotts Pharma, Chiesi, Casen Fleet, Gebro Pharma, Otsuka Pharmaceutical, Vifor Pharma. The remaining authors declare that they have no conflict of interest.

\section{References}

1. Chaparro M, Panes J, Garcia V, et al. Long-term durability of infliximab treatment in Crohn's disease and efficacy of dose "escalation" in patients losing response. J Clin Gastroenterol. 2011;45:113-118.

2. Chaparro M, Panes J, Garcia V, et al. Long-term durability of response to adalimumab in Crohn's disease. Inflamm Bowel Dis. 2012;18:685-690.

3. Gisbert JP, Panes J. Loss of response and requirement of infliximab dose intensification in Crohn's disease: a review. Am J Gastroenterol. 2009;104:760-767.
4. Chaparro M, Guerra I, Munoz-Linares P, et al. Systematic review: antibodies and anti-TNF-alpha levels in inflammatory bowel disease. Aliment Pharmacol Ther. 2012;35:971-986.

5. Vande Casteele N, Ferrante M, Van Assche G, et al. Trough concentrations of infliximab guide dosing for patients with inflammatory bowel disease. Gastroenterology. 2015;148:e1323.

6. D'Haens G, Vermeire S, Lambrecht G, et al. OP029 Drug-concentration versus symptom-driven dose adaptation of Infliximab in patients with active Crohn's disease: a prospective, randomised, multicentre trial (Tailorix). J Crohns Colitis. 2016;10:S24.

7. Feuerstein JD, Nguyen GC, Kupfer SS, et al. American Gastroenterological Association Institute Clinical Guidelines C. American Gastroenterological Association Institute Guideline on therapeutic drug monitoring in inflammatory bowel disease. Gastroenterology. 2017;153:827-834.

8. Gomollon F, Dignass A, Annese V, et al. 3rd European evidence-based consensus on the diagnosis and management of Crohn's disease 2016: part 1: diagnosis and medical management. J Crohns Colitis. 2017;11:3-25.

9. Steenholdt C, Ainsworth MA, Tovey M, et al. Comparison of techniques for monitoring infliximab and antibodies against infliximab in Crohn's disease. Ther Drug Monit. 2013;35:530-538.

10. Vande Casteele N, Buurman DJ, Sturkenboom MG, et al. Detection of infliximab levels and anti-infliximab antibodies: a comparison of three different assays. Aliment Pharmacol Ther. 2012;36:765-771.

11. Peyrin-Biroulet L, Sandborn W, Sands BE, et al. Selecting therapeutic targets in inflammatory bowel disease (STRIDE): determining therapeutic goals for treat-to-target. Am J Gastroenterol. 2015;110:1324-1338.

12. Harris PA, Taylor R, Thielke R, et al. Research electronic data capture (REDCap) — a metadata-driven methodology and workflow process for providing translational research informatics support. J Biomed Inform. 2009;42:377-381.

13. Daperno M, D'Haens G, Van Assche G, et al. Development and validation of a new, simplified endoscopic activity score for Crohn's disease: the SES-CD. Gastrointest Endosc. 2004;60:505-512.

14. Rutgeerts P, Geboes K, Vantrappen G, et al. Predictability of the postoperative course of Crohn's disease. Gastroenterology. 1990;99:956-963.

15. Sutherland LR, Martin F, Greer S, et al. 5-Aminosalicylic acid enema in the treatment of distal ulcerative colitis, proctosigmoiditis, and proctitis. Gastroenterology. 1987;92:1894-1898.

16. Imaeda $\mathrm{H}$, Bamba $\mathrm{S}$, Takahashi $\mathrm{K}$, et al. Relationship between serum infliximab trough levels and endoscopic activities in patients with Crohn's disease under scheduled maintenance treatment. J Gastroenterol. 2014;49:674-682.

17. Roblin X, Marotte H, Rinaudo M, et al. Association between pharmacokinetics of adalimumab and mucosal healing in patients with inflammatory bowel diseases. Clin Gastroenterol Hepatol. 2014; $12:$ e82.

18. Reinisch W, Colombel JF, Sandborn WJ, et al. Factors associated with short- and long-term outcomes of therapy for Crohn's disease. Clin Gastroenterol Hepatol. 2015;13:e532.

19. Zittan E, Kabakchiev B, Milgrom R, et al. Higher adalimumab drug levels are associated with mucosal healing in patients with Crohn's disease. J Crohns Colitis. 2016;10:510-515.

20. Yarur AJ, Jain A, Hauenstein SI, et al. Higher adalimumab levels are associated with histologic and endoscopic remission in patients with Crohn's disease and ulcerative colitis. Inflamm Bowel Dis. 2016;22:409-415. 
21. Ungar B, Levy I, Yavne Y, et al. Optimizing anti-TNF-alpha therapy: serum levels of infliximab and adalimumab are associated with mucosal healing in patients with inflammatory bowel diseases. Clin Gastroenterol Hepatol. 2016;14:e552.

22. Morita $\mathrm{Y}$, Imaeda $\mathrm{H}$, Nishida $\mathrm{A}$, et al. Association between serum adalimumab concentrations and endoscopic disease activity in patients with Crohn's disease. J Gastroenterol Hepatol. 2016;31:1831-1836.
23. Hindryckx P, Novak G, Vande Casteele N, et al. Review article: dose optimisation of infliximab for acute severe ulcerative colitis. Aliment Pharmacol Ther. 2017;45:617-630.

24. Nunes T, Etchevers MJ, Domenech E, et al. Smoking does influence disease behaviour and impacts the need for therapy in Crohn's disease in the biologic era. Aliment Pharmacol Ther. 2013;38:752-760.

\section{Affiliations}

María Chaparro ${ }^{1,18}$ - Manuel Barreiro-de Acosta ${ }^{2} \cdot$ Ana Echarri $^{3} \cdot$ Rosendo Almendros $^{4}$ - Jesús Barrio ${ }^{5}$. Jordina Llao . $^{6}$ Fernando Gomollón ${ }^{7,18}$. Maribel Vera ${ }^{8}$. José Luis Cabriada ${ }^{9}$. Jordi Guardiola ${ }^{10}$ • Iván Guerra ${ }^{11}$ • Belén Beltrán ${ }^{12,18}$. Oscar Roncero ${ }^{13}$. David Busquets ${ }^{14}$. Carlos Taxonera ${ }^{15} \cdot$ Xavier Calvet $^{16,18} \cdot$ Rocío Ferreiro-Iglesias $^{2}$. Virginia Ollero Pena ${ }^{3} \cdot$ David Bernardo ${ }^{1,18} \cdot$ María G. Donday $^{1,18} \cdot$ Ana Garre $^{1,18} \cdot$ Ana Godino $^{17} \cdot$ Ana Díaz $^{17}$. Javier P. Gisbert ${ }^{1,18}$

1 Servicio de Aparato Digestivo, Hospital Universitario de La Princesa e Instituto de Investigación Sanitaria Princesa (IISIP), Madrid, Spain

2 Servicio de Aparato Digestivo, Hospital Clínico Universitario de Santiago, Santiago de Compostela, Spain

3 Servicio de Aparato Digestivo, Complejo Hospitalario Universitario de Ferrol, Coruña, Spain

4 Servicio de Farmacia, Hospital Universitario Rio Hortega, Valladolid, Spain

5 Servicio de Aparato Digestivo, Hospital Universitario Rio Hortega, Valladolid, Spain

6 Servicio de Aparato Digestivo, Hospital de la Santa Creu i Sant Pau, Barcelona, Spain

7 Servicio de Aparato Digestivo, Hospital Clínico Universitario Lozano Blesa and IIS-Aragón, Saragossa, Spain

8 Servicio de Aparato Digestivo, Hospital Universitario Puerta de Hierro, Majadahonda, Spain

9 Servicio de Aparato Digestivo, Hospital Galdakao-Usansolo, Vizcaya, Spain

10 Servicio de Aparato Digestivo, Hospital Universitari de Bellvitge-IDIBELL, Universidad de Barcelona, Barcelona, Spain
11 Servicio de Aparato Digestivo, Hospital Universitario de Fuenlabrada, Madrid, Spain

12 Servicio de Aparato Digestivo, Hospital Universitari La Fe, Valencia, Spain

13 Servicio de Aparato Digestivo, Complejo Hospitalario la Mancha Centro, Ciudad Real, Spain

14 Servicio de Aparato Digestivo, Hospital Universitari de Girona Doctor Josep Trueta, Girona, Spain

15 Servicio de Aparato Digestivo, Hospital Clínico San Carlos and Instituto de Investigación del Hospital Clínico San Carlos (IdISSC), Madrid, Spain

16 Servicio de Aparato Digestivo, Corporació Sanitària Parc Taulí, Sabadell, Barcelona, Spain

17 Servicio de Análisis Clínicos, Hospital Universitario de La Princesa e Instituto de Investigación Sanitaria Princesa (IIS-IP), Madrid, Spain

18 Centro de Investigación Biomédica en Red de Enfermedades Hepáticas y Digestivas (CIBEREHD), Madrid, Spain 